\title{
A NUTRIENT METHOD FOR CUTIVATION OF MACROALGAE Ulva papenfussii
}

\author{
Vo Thanh Trung ${ }^{1, *}$, Tran Van Huynh ${ }^{1}$, Tran Mai Duc ${ }^{1}$, \\ Pham Duc Thinh ${ }^{1}$, Pham Trung San ${ }^{1}$, Nguyen Thanh Hang ${ }^{2}$ \\ ${ }^{1}$ Nha Trang Institute of Technology Reasearch and Aplication, VAST, Vietnam \\ ${ }^{2}$ School of Biotechnology and Food Technology, Hanoi University \\ of Science and Technology, Vietnam
}

Received 26 May 2018, accepted 7 March 2019

\begin{abstract}
Macroalgae species of the genus Ulva are widely distributed in the wild, many species of this genus has been used as food as an attractive material for the study of materials, fuels, food etc.. In this paper, we are focusing on nutrient method for cultivation of Ulva papenfussii and A nutrient source for cultivation of $U$. papenfussii was also investigated with the perspective of utilizing the produced biomass for feed. $U$. papenfussii is fragmented into $1 \times 1 \mathrm{~cm}$ size, then it keep in Ulva extract of $0.1 \mathrm{~g} / \mathrm{l}$ concentrate for 7 days. Then continue to keep fragments in the following conditions: $20 \mathrm{ml} / 1$ of PES medium, $700 \mu \mathrm{mol}$ photon $/ \mathrm{m}^{2} / \mathrm{s}$ of light, $25^{\circ} \mathrm{C}$ of temperature, $3 \%$ of salinity, 28 days of time. Under this condition the productivity $U$. papenfussii was $17.8 \mathrm{~g} / \mathrm{l}$ of weight and its growth rate was $4.3-6.5 \%$ day. Nutritional cultivation is successful for $U$. papenfussii speceies, which is of great importance to study the potential of producing seaweed varieties like blades for commercial application of seaweed species.
\end{abstract}

Keywords: Ulva papenfussii, cutivation, fragmented, nutrient method.

Citation: Vo Thanh Trung, Tran Van Huynh, Tran Mai Duc, Pham Duc Thinh, Pham Trung San, Nguyen Thanh Hang, 2019. A nutrient method for cutivation of macroalgae Ulva papenfussii. Tap chi Sinh hoc, 41(1): 91-99. https://doi.org/10.15625/0866-7160/v41n1.12590.

*Corresponding author email: vothanhtrung@ nitra.vast.vn

@2019 Vietnam Academy of Science and Technology (VAST) 


\title{
NGHIÊN CÚU KỸ THUẬT NUÔI DINH DƯỠNG RONG Ulva papenfussii
}

\author{
Võ Thành Trung ${ }^{1, *}$, Trần Văn Huynh ${ }^{1}$, Trần Mai Đức ${ }^{1}$, \\ Phạm Đức Thịnh ${ }^{1}$, Phạm Trung Sản ${ }^{1}$, Nguyễn Thanh Hằng ${ }^{2}$ \\ ${ }^{1}$ Viện Nghiên cứu và Ứng dụng Công nghệ Nha Trang, Viện Hàn lâm KHCNVN \\ ${ }^{2}$ Viện Công nghệ Sinh học và Công nghệ Thực phẩm, Trường Đại học Bách Khoa Hà Nội
}

Ngày nhận bài 26-5-2018, ngày chấp nhận 7-3-2019

\section{TÓM TẮT}

Chi rong lục Ulva gồm những loài phát triển phổ biến trong tự nhiên, nhiều loài đã được người dân ven biển sử dụng làm thực phẩm và là nguyên liệu tiềm năng cho các nghiên cứu vật liệu và nhiên liệu. Trong nghiên cứu này, chúng tôi tiến hành nghiên cứu nuôi dinh dưỡng $U l v a$ papenfussii, một loài có kích thước lớn, thích hợp cho nuôi trồng. $U$. papenfussii được phân mảnh thành kích thước $\mathrm{d} 3=1 \times 1 \mathrm{~cm}$, được giữ ổn định trong chất nền dịch chiết rong Ulva nồng độ $0,1 \mathrm{~g} / \mathrm{l}$ trong thời gian 7 ngày. Sau đó tiếp tục nuôi các mảnh rong trong theo điều kiện: nồng độ mảnh rong $4 \mathrm{~g} / \mathrm{l}$, môi trường PES $20 \mathrm{ml} / \mathrm{l}$, ánh sáng $700 \mu \mathrm{mol}$ photon $/ \mathrm{m}^{2} / \mathrm{s}$, nhiệt độ $25^{\circ} \mathrm{C}$, độ mặn $3 \%$, thời gian 28 ngày. Kết quả quá trình nuôi tạo ra $17,8 \mathrm{~g} / \mathrm{l}$ rong với tốc độ sinh trưởng cao đạt 4-6,5\% ngày. Nuôi dinh dưỡng rong $U$. papenfussii thành công có ý nghĩa quan trọng trong sản xuất giống các loài rong biển dạng phiến cho ứng dụng nuôi thương phẩm.

Từ khóa: Ulva papenfussii, nuôi dinh dưỡng, phân mảnh.

*Địa chỉ liên hệ email: vothanhtrung@nitra.vast.vn

\section{MỞ DÀ̀U}

Rong biển là nguyên liệu thích hợp đáp ứng được các mục tiêu tạo ra chế phẩm sinh học, thực phẩm sạch, đã có những nghiên cứu chỉ ra rong Ulva được ứng dụng sản xuất nhiên liệu sinh học. Theo Annattte (2011), rong $U$. lactuca được lên men kỵ khí để sản xuất khí metan, $U$. faciata sử dụng cho sản xuất ethanol (Nitin, 2013) và rong Ulva còn cho nhiều loại sản phẩm nhiên liệu khác (Nawei, 2013). Trong lĩnh vực ứng dụng làm thực phẩm, rong Ulva là loại thực phẩm sạch trong nhiều bữa ăn của người Việt (Dang Diem Hong et al., 2007). Hai loài rong, $U$. reticulata và $U$. lactuca, có chứa nhiều loại acid amin và khoáng vi lượng, các chất này có lợi cho sức khỏe người sử dụng. Theo nghiên cứu Myonglae (2010), các dẫn xuất polysaccharid từ rong Ulva có ứng dụng rất lớn trong sản xuất thực phẩm chức năng và chế phẩm trong y học. Do những công dụng của rong Ulva, nghiên cứu kỹ thuật nuôi rong Ulva bằng công nghệ sạch để tạo ra nguyên liệu cho các ứng dụng rất có ý nghĩa thực tiễn.

Ulva là chi rong lục rất phổ biến, hình thái thường thấy của chi này ở hai dạng ống và dạng phiến, trong đó $U$. intestinalis, $U$. compressa và $U$. torta có dạng ống, còn $U$. reticulata, $U$. lactuca và $U$. papenfusii có dạng phiến. Chi Ulva phân bố rộng thích nghi với dải độ mặn lớn từ 2 đến $35 \%$ và phát triển nhanh trong điều kiện giàu dinh dưỡng, đặc biệt nguồn nitrogen. Các loài thuộc chi Ulva sống được trên nhiều loại giá thể khác nhau như mảnh gỗ, vỏ sò, đá sỏi, đáy bùn... Chính vì vậy, sự phân bố trong tự nhiên của các loài thuộc chi này rất rộng. Rong Ulva có hình thức sinh sản hữu tính (Dawson, 1956). Thông thường vào mùa vụ sinh sản, rong Ulva sẽ thụ tinh sau đó hình thành hạt, các hạt này được 
lưu giữ trong môi trường gặp và khi điều kiện thuận lợi chúng sẽ hình thành tản rong. Quá trình sinh sản này có chu kỳ kéo dài một năm. Vì vậy, để rút ngắn quá trình sản xuất giống, cần tiến hành phân mảnh rong Ulva để nuôi sinh khối rong này được xem là phương pháp nuôi có tiềm năng thành công cao.

\section{VÂT LIỆ VÀ PHƯƠNG PHÁP NGHIÊN CƯU}

Các mẫu rong nghiên cứu thuộc loài Ulva papenfussii Linnaeus, được thu tại khu vực biển Hòn Chồng, thành phố Nha Trang, tỉnh Khánh Hòa. Mẫu được thu vào tháng 12/2017 (hình P1).

Môi trường $\mathrm{PES}$ (Provasoli's enriched seawater medium) có thành phần $\mathrm{NaNO}_{3} 350$ mg, $\mathrm{Na}_{2}$ glycerophosphate $5 \mathrm{H}_{2} \mathrm{O} 50 \mathrm{mg}, \mathrm{Fe} 25$ $\mathrm{ml}$, vitamin $\mathrm{B} 1210 \mu \mathrm{g}$, thiamine $0,5 \mathrm{mg}$; biotin $5 \mu \mathrm{g} ; \mathrm{Na}_{2}$ EDTA $100 \mathrm{mg} ; \mathrm{H}_{3} \mathrm{BO}_{3} 114$ mg; $\mathrm{FeCl}_{3} 6 \mathrm{H}_{2} \mathrm{O}$ 4,9 mg; $\mathrm{MnSO}_{4} \mathrm{H}_{2} \mathrm{O} \quad 16,4$ $\mathrm{mg} ; \mathrm{ZnSO}_{4} 7 \mathrm{H}_{2} \mathrm{O} 2,2 \mathrm{mg} \mathrm{COSO}_{4} .7 \mathrm{H} 2 \mathrm{O}$ $0,48 \mathrm{mg}$; Tris buffer $500 \mathrm{mg}$; pH 7,8 pha trong 1 lít Bold and Wynne (1978).

Xác định tỷ lệ sống chết của mảnh rong theo phương pháp đếm trực tiếp, mảnh còn sống sắc tố bình thường mảnh rong có màu xanh, mảnh chết sắc tố mất hết mảnh rong có màu trắng.

Xác định nhiệt độ bằng nhiệt kế thủy ngân; độ mặn được xác định bằng khúc xạ kế Salinometer (Shibuya, Japan); ánh sáng LI250A Light Metter.

Khối lượng rong được đo bằng cân điện tử (KP, Maxel 500, Taiwan).

Xác định tốc độ tăng trưởng theo công thức $S G R\left(\% d^{-1}\right)=\left[\ln \left(W_{t} / W_{o}\right)\right] / t \times 100 \%$; trong đó $W_{o}=$ Khối lượng rong ở thời điểm ban đầu, $W_{t}=$ Khối lượng rong ở thời điểm $t$ Brinkhuis (1985).

Phương pháp nuôi dinh dưỡng rong $U$. papenfussii

\section{Xủ lý rong bố me}

Rong bố mẹ được thu hái tại các bãi triều ven biển tỉnh Khánh Hòa được giữ trong các túi vải, không cho rong tiếp xúc ánh sáng trong quá trình vận chuyển, thời gian vận chuyển về bể nuôi nhanh không quá 1 giờ.
Các thao tác này giúp giữ ẩm cho rong và giúp tản rong không bị tổn thương và biến đổi sắc tố. Tản rong được cho vào bế nuôi rong. Quá trình xử lý nêu trên đã giúp cho các tản rong bố mẹ thích nghi được tốt với điều kiện nuôi thí nghiệm, thời gian lưu giữ tản rong bố mẹ 10 ngày trước khi tiến hành nhân giống.

\section{Sản xuất rong giống $U$. papenfussii bằng} hình thức phân mảnh

\section{Xỉ lý mảnh rong (hình P2)}

Tản rong Ulva được phân mảnh thành các kích thước khác nhau d1 $=0,2 \times 0,2 \mathrm{~cm} ; \mathrm{d} 2=$ $0,5 \times 0,5 \mathrm{~cm} ; \mathrm{d} 3=1 \times 1 \mathrm{~cm} ; \mathrm{d} 4=2 \times 2 \mathrm{~cm}$. Sau đó lấy 50 mảnh rong của mỗi loại kích thước cho vào lọ có chứa $200 \mathrm{ml}$ các loại chất nền khác nhau, gồm : dịch chiết rong Ulva, alginate, carrageenan, agar có cùng nồng độ $0,1 \mathrm{~g} / \mathrm{l}$ và nước biển nguyên chất đã được hấp khữ trùng, giữ ở nhiệt độ $25^{\circ} \mathrm{C}$, độ mặn $3 \%$, chiếu ánh sáng $700 \pm 35 \mu \mathrm{mol}$ photon $/ \mathrm{m}^{2} / \mathrm{s}$, nuôi các mảnh rong 7 ngày rồi xác định tỷ lệ sống chết, từ đó chọn chất nền thích hợp cho xử lý mảnh rong.

\section{Nuôi dinh dưỡng mảnh rong giống $U$. papenfussii (hình P2)}

\section{Khảo sát sinh trưởng của các loại kích thước mảnh}

Các loại kích thước mảnh được nuôi trong điều kiện: Mật độ $4 \mathrm{~g} / \mathrm{l}$, nhiệt độ $25^{\circ} \mathrm{C}$, ánh sáng $700 \pm 35 \mu \mathrm{mol}$ photon $/ \mathrm{m}^{2} / \mathrm{s}$, độ mặn $3 \%$, PES $20 \mathrm{ml} / \mathrm{l}$, thời gian nuôi 28 ngày. Sau đó xác định lượng sinh khối tăng và tốc độ tăng sinh khối để chọn ra kích thước mảnh thích hợp cho quá trình nuôi.

\section{Khảo sát các yếu tố ảnh hưởng đến quá trình nuôi mảnh}

Bố trí các thí nghiệm nghiên cứu sự thay đổi: Mật độ rong 2; 4; 6; 8 và 10 g/l; nhiệt độ, $20 ; 25 ; 30$ và $35^{\circ} \mathrm{C}$; ánh sáng, $300 ; 700$ và $1100 \mu \mathrm{mol} \mathrm{photon} / \mathrm{m}^{2} / \mathrm{s}$, độ mặn $2 ; 2,5 ; 3$ và $3,5 \%$, dinh dưỡng PES $10 ; 20 ; 30$ và $40 \mathrm{ml} / 1$. Sau khi kết thúc khảo sát các yếu tố ảnh hưởng đến quá trình nuôi dinh dưỡng mảnh rong giống $U$. papenfusii, chúng tôi sẽ chọn được điều kiện thích hợp của quá trình nuôi. 


\section{KẾT QUẢ NGHIÊN CỨU}

Sản xuất rong giống $U$. papenfussii bằng hình thức phân mảnh

Tản rong $U$. papenfussii được phân mảnh thành các kích thước $\mathrm{d} 1, \mathrm{~d} 2, \mathrm{~d} 3$ và $\mathrm{d} 4$ rồi được nuôi trong các môi trường chất mền khác nhau, gồm nước biển nguyên chất, dịch chiết rong Ulva, alginate, carrageenan và agar. Mục đích của quá trình này là làm lành vêt thương của mảnh rong nâng cao tỷ lệ sống cho các mảnh. Kết quả nghiên cứu thể hiện ở bảng 1 .

Kết quả bảng 1 chỉ ra các mảnh rong vừa được phân mảnh sau đó giữ trong chất nền nước biển, carragennan và agar có tỷ lệ sống không cao. Trong khi đó, các mảnh rong được giữ trong chất nền alginate và dịch chiết rong Ulva có tỷ lệ sống cao. Các mảnh d1, d2 có tỷ lệ sống thấp, chỉ đạt 43-58\%, do kích thước các mảnh $\mathrm{d} 1, \mathrm{~d} 2$ nhỏ rất dễ bị tổn thương bởi các tác động của môi trường nuôi. Các mảnh $\mathrm{d} 3$ và $\mathrm{d} 4$ có tỷ lệ sống cao 73-96\%, đặc biệt khi $\mathrm{d} 3$ và $\mathrm{d} 4$ được giữ trong chất nền là dịch chiết rong Ulva có tỷ lệ sống đạt đến $96 \%$. Điều này cho thấy, dịch chiết từ rong Ulva tốt hơn agar, carragennan, alginate và nước biển, vì dịch chiết Ulva có đầy đủ các chất cần thiết cho việc phục hồi tổn thương của các mảnh $\mathrm{d} 1, \mathrm{~d} 2, \mathrm{~d} 3$ và $\mathrm{d} 4$. Chính vì vậy, sử dụng dịch chiết Ulva để xử lý các mảnh rong, và chọn $\mathrm{d} 3$ làm giống rong để nuôi thương phẩm là thích hợp.

Bảng 1 . Tỷ lệ sống của các loại mảnh rong $U$. papenfussii trong các môi trường chất nền khác nhau

\begin{tabular}{|l|c|c|c|c|}
\hline \multirow{2}{*}{ Chất nền } & \multicolumn{4}{|c|}{ Tỷ lệ sống của mảnớc mảnh rong $(\%)$} \\
\cline { 2 - 5 } & $\mathrm{d} 1$ & $\mathrm{~d} 2$ & $\mathrm{~d} 3$ & $\mathrm{~d} 4$ \\
\hline Nước biển & $43,0 \pm 1,5$ & $62,0 \pm 1,7$ & $78,0 \pm 1,3$ & $81,0 \pm 1,4$ \\
\hline Alginate & $56,0 \pm 1,2$ & $69,0 \pm 1,1$ & $83,0 \pm 1,7$ & $87,0 \pm 1,5$ \\
\hline Carragennan & $40,0 \pm 0,8$ & $58,0 \pm 0,9$ & $73,0 \pm 1,1$ & $75,0 \pm 1,1$ \\
\hline Agar & $35,0 \pm 0,3$ & $45,0 \pm 0,5$ & $53,0 \pm 0,8$ & $61,0 \pm 0,7$ \\
\hline Dịch chiết rong Ulva & $62,0 \pm 0,9$ & $78,0 \pm 1,3$ & $\mathbf{9 6 , 0} \pm 1,9$ & $\mathbf{9 6 , 0} \pm 2,0$ \\
\hline
\end{tabular}

Nuôi dinh dưỡng mảnh rong giống $U$. papenfussii

Khảo sát sinh trưởng của các loại mảnh có kích thước khác nhau
Các mảnh rong sau khi được xử lý sẽ được nuôi trong 28 ngày để xác định lượng tăng sinh khối và tốc độ tăng trưởng của các loại kích thước khác nhau. Kết quả được thể hiện bảng 2.

Bảng 2. Tốc độ tăng trưởng, lượng sinh khối tăng của các kích thước mảnh theo thời gian

\begin{tabular}{|l|c|c|c|c|c|c|c|c|}
\hline $\begin{array}{c}\text { Thời gian } \\
\text { (ngày) }\end{array}$ & \multicolumn{4}{|c|}{ Lượng sinh khối tăng $(\mathrm{g})$} & \multicolumn{4}{c|}{$\begin{array}{c}\text { Tốc độ tăng trường } \\
\text { (\%ngày) }\end{array}$} \\
\hline & $\mathrm{d} 1$ & $\mathrm{~d} 2$ & $\mathrm{~d} 3$ & $\mathrm{~d} 4$ & $\mathrm{~d} 1$ & $\mathrm{~d} 2$ & $\mathrm{~d} 3$ & $\mathrm{~d} 4$ \\
\hline 0 & 4 & 4 & 4 & 4 & & & & \\
\hline 7 & $4,8 \pm 0,1$ & $5,2 \pm 0,1$ & $5,4 \pm 0,16$ & $5,5 \pm 0,1$ & 2,6 & 3,7 & 4,3 & 4,5 \\
\hline 14 & $6,2 \pm 0,12$ & $7,3 \pm 0,1$ & $8,5 \pm 0,19$ & $8,6 \pm 0,2$ & 3,7 & 4,8 & 6,5 & 6,4 \\
\hline 21 & $9,1 \pm 0,15$ & $10,5 \pm 0,12$ & $12,9 \pm 0,25$ & $12,9 \pm 0,26$ & 5,9 & 5,2 & 6,0 & 5,8 \\
\hline 28 & $12,6 \pm 0,2$ & $14,4 \pm 0,27$ & $\underline{\mathbf{1 7 , 8} \pm \mathbf{0 , 3}}$ & $\underline{\mathbf{1 7 , 8} \pm \mathbf{0 , 3}}$ & 4,2 & 4,5 & 4,6 & 4,6 \\
\hline \multicolumn{7}{|l|}{ Trung bình } \\
\hline
\end{tabular}

Kết quả nuôi các dạng mảnh rong cho thấy, tất cả các loại mảnh đều tăng khối lượng sau 28 ngày nuôi. Khối lượng của d1, d2 tăng không cao dao động khoảng 12-14 (g), và tốc 
độ tăng trưởng của $\mathrm{d} 1$ và $\mathrm{d} 2$ thấp hơn $\mathrm{d} 3$ và $\mathrm{d} 4$. Trong khi đó $\mathrm{d} 3$ và $\mathrm{d} 4$ có khối lượng tăng trọng cao với tốc độ tăng trưởng cao đạt 5,3\% ngày. Vì vậy mảnh $\mathrm{d} 3$ và $\mathrm{d} 4$ là thích hợp được chọn để nuôi trồng thu sinh khối. Bên cạnh đó kích thước tản rong $U$. papenfussii trưởng thành đạt $20 \mathrm{~cm} \times 30 \mathrm{~cm}=600 \mathrm{~cm}^{2}$, tương ứng với khoảng 600 mảnh $\mathrm{d} 3$ và 300 mảnh $\mathrm{d} 4$. Điều này cho thấy kích thước mảnh loại $\mathrm{d} 3$ đã sản xuất được nhiều giống hơn $\mathrm{d} 4$, do đó $\mathrm{d} 3$ được chọn cho nuôi khảo sát các yếu tố ảnh hưởng.

\section{Khảo sát các yếu tố ảnh huởng đến quá trình nuôi mảnh}

Tản rong $U$. papenfussii được phân mảnh thành kích thước $\mathrm{d} 3$ được xử lý với dịch chiết rong Ulva rồi được nuôi khảo sát các yếu tố ảnh hưởng: mật độ rong $2 ; 4 ; 6 ; 8$ và $10 \mathrm{~g} / \mathrm{l}$; nhiệt độ $20 ; 25 ; 30$ và $35^{\circ} \mathrm{C}$; ánh sáng, 300 ; 700 và $1100 \mu \mathrm{mol}$ photon $/ \mathrm{m}^{2} / \mathrm{s}$, độ mặn, 2 ; 2,$5 ; 3$ và $3,5 \%$, dinh dưỡng $10 ; 20 ; 30$ và 40 $\mathrm{ml} / \mathrm{l}$. Kết quả khảo sát được trình bày ở các hình $1,2,3,4,5,6$.

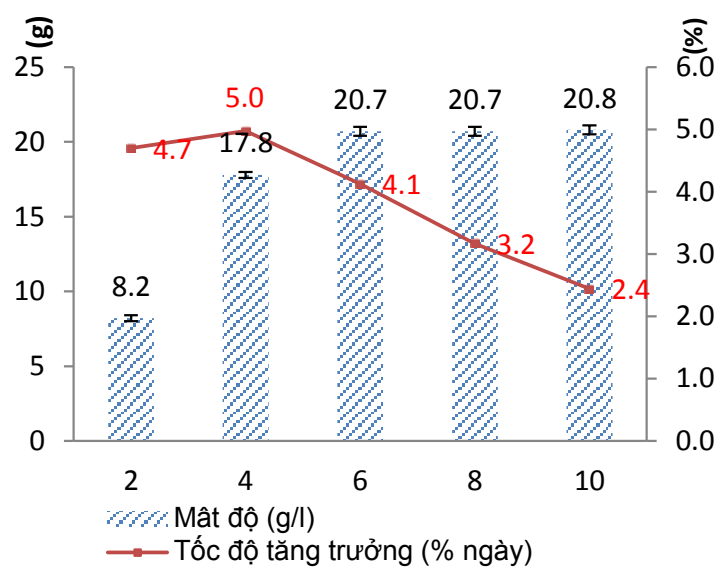

Hình 1 Ảnh hưởng của mật độ

Hình 1 cho thấy, trong quá trình nuôi 28 ngày tất cả công thức thí nghiệm đều tăng về khối lượng. Tại mật độ $10 \mathrm{~g} / \mathrm{l}$ có khối lượng rong tăng cao nhất đạt $20,8 \mathrm{~g}$ trong đó, mật độ $2 \mathrm{~g} / \mathrm{l}$ có khối lượng rong tăng thấp nhất đạt 8,2 $\mathrm{g} / \mathrm{l}$. Nhưng nếu xét theo tốc độ tăng trưởng thì tại mật độ $4 \mathrm{~g} / \mathrm{l}$ có tốc độ tăng trưởng cao nhất $5 \%$ ngày đạt khối lượng $17,8 \mathrm{~g}$, trong khi đó các mật độ khác chỉ đạt 3,2-4,7\% ngày. Vì vậy, mật độ nuôi 4 g/l thích hợp cho nuôi thương phẩm.

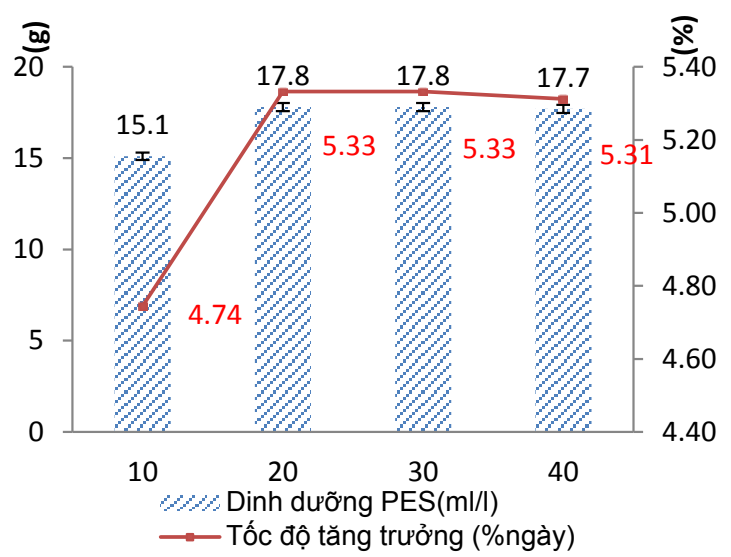

Hình 2. Ảnh hưởng của dinh dưỡng



Hình 3. Ảnh hưởng của nhiệt độ

Hình 2 cho thấy kích thước loại d3 được nuôi với dinh dưỡng PES tăng về khối lượng và đạt khối lượng 15-17,8 g/l. Trong đó nồng độ dinh dưỡng PES $10 \mathrm{ml} / \mathrm{l}$ cho kết quả thấp hơn các nồng độ PES 20,30, 40 ml/l. Nồng độ dinh dưỡng thích hợp được lựa chọn là PES $20 \mathrm{ml} / 1$ vì ở nồng độ này sẽ tiết kiệm được dinh dưỡng và không gây lãng phí.

Hình 3 cho thấy mảnh rong $\mathrm{d} 3$ được nuôi ở các nhiệt độ khác nhau, trong đó nhiệt độ $20^{\circ} \mathrm{C}$ cho rong có khối lượng và tốc độ tăng trưởng thấp hơn so với nhiệt độ $25-30^{\circ} \mathrm{C}$. Khi nhiệt độ tăng đến $35^{\circ} \mathrm{C}$ tốc độ tăng trưởng và khối lượng tăng thấp. Như vậy, nhiệt độ thích hợp cho rong phát triển là $25-30^{\circ} \mathrm{C}$. 


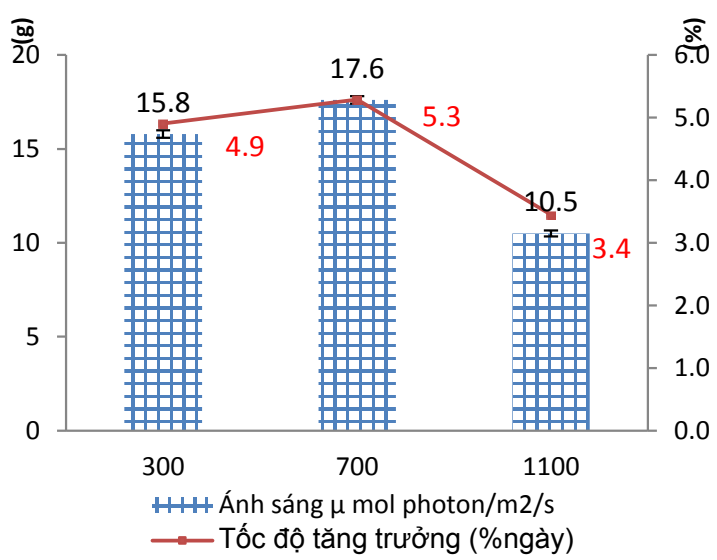

Hình 4. Ảnh hưởng của ánh sáng

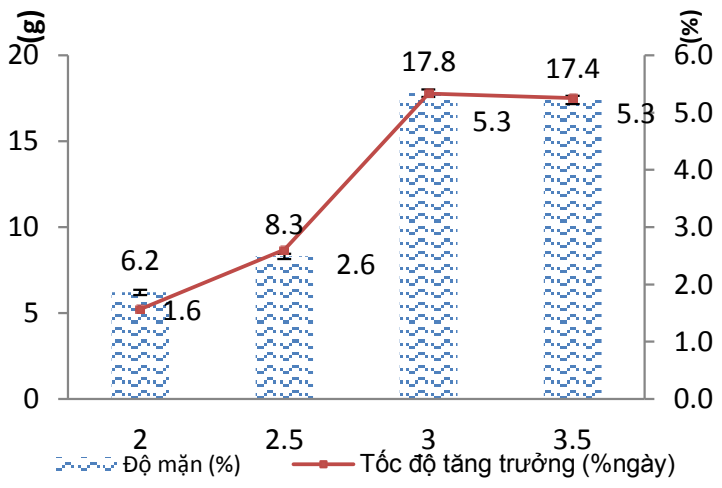

Hình 5. Ảnh hưởng của độ mặn

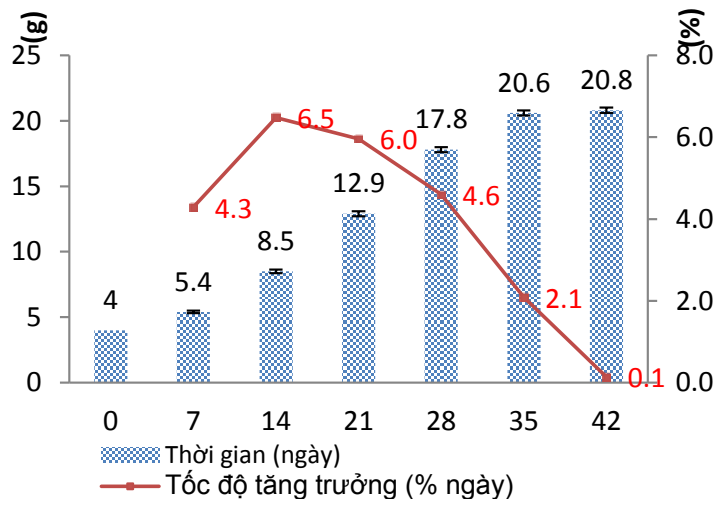

Hình 6. Ảnh hưởng của thời gian

Hình 4 cho thấy rõ cường độ ánh sáng có ảnh hưởng lớn lên quá trình nuôi mảnh. Trong đó mảnh rong sống trong cường độ lớn 1.100 $\mu \mathrm{mol}$ photon $/ \mathrm{m}^{2} / \mathrm{s}$ có tốc độ sinh trưởng thấp hơn nhiều so với cường độ ánh sáng yếu 300 và $700 \mu$ mol photon, và tại cường độ 700 $\mu$ mol photon, mảnh rong có tốc độ sinh trưởng tốt nhất đạt 5,3\% ngày và có khối lượng 17,7 g. Hình 5 cho thấy độ mặn ở 2-2,5\%, mảnh rong sinh trưởng chậm chỉ đạt khối lượng 6-8,3 g. Trong khi đó ở độ mặn 3-3,5\% rong đạt khối lượng đến 17,4-17,8 $\mathrm{g}$.

Hình 6 cho thấy sinh trưởng của rong trong khoảng thời gian 42 ngày. Khối lượng mảnh rong tăng chậm trong khoảng thời gian từ $0-7$ ngày, từ ngày thứ $7-28$, rong tăng nhanh, đạt sinh khối từ $5,4 \mathrm{~g}$ lên $17,8 \mathrm{~g}$, các ngày tiếp theo khối lượng rong có tăng nhưng không đáng kể và cao nhất đạt $20,8 \mathrm{~g} \mathrm{sau} 42$ ngày nuôi. Trong suốt thời gian nuôi, tốc độ sinh trưởng của rong tốt nhất từ ngày thứ 7 đến ngày thứ 28 , tốc độ sinh trưởng giai đoạn này đạt 4,3-6,5\% ngày, còn các giai đoạn khác tốc độ sinh trưởng đều thấp.

Như vậy, có thể thấy điều kiện giúp mảnh rong sinh trưởng tốt là $4 \mathrm{~g}$ mảnh rong có kích thước $1 \times 1 \mathrm{~cm}$ được nuôi trong môi trường có bổ sung $20 \mathrm{ml} / 1$ môi trường PES, nuôi ở nhiệt độ $25^{\circ} \mathrm{C}$, cường độ ánh sáng $700 \mu \mathrm{mol}$ photon $/ \mathrm{m}^{2} / \mathrm{s}$, độ mặn $3 \%$, thời gian 28 ngày.

\section{THẢO LUÂN}

Theo Hiraoka (1998), tế bào rong Ulva bị ảnh hưởng rõ rệt bởi các yếu tố môi trường như ánh sáng, nhiệt độ, độ muối, dinh dưỡng và $\mathrm{pH}$ trong quá trình nuôi mảnh rong, ảnh hưởng này có thể thấy khinuôi mảnh rong $U$. mutablis có kích thước là $0,5 \times 0,5 \mathrm{~cm}$ (Nordpy, 1977) hoặc nuôi mảnh rong $U$. lactuca có kích thước nhỏ hơn $1 \times 2 \mathrm{~cm}$ (Prue Pettett, 2009). Còn trong nhiên cứu này của chúng tôi, ảnh hưởng rõ khi $\mathrm{c}$ nuôi rong $U$. papenfussii kích thước $1 \times 1 \mathrm{~cm}$.

Theo Prue Pettett (2009), rong U. lactuca được nuôi với nồng độ $10 / 3$ lít, tương ứng 3,3 g/l, Theo công bố của Xiao jie (2016) đã cho thấy $U$. prolifera được nuôi với nồng độ $1 \mathrm{~g} / \mathrm{l}$ và $\mathrm{khi}$ rong tăng trọng đến $20 \mathrm{~g} / \mathrm{l}$ thì dừng lại. Điều này có thể thấy nồng độ nuôi $4 \mathrm{~g} / \mathrm{l}$ rong $U$. papenfussii trong nghiên cứu của chúng tôi là thích hợp so với các nghiên cứu đã công bố trước đây.

Cũng theo Prue Pettett (2009), rong $U$. lactuca, U. intestinalis, $U$. prolifera được nuôi 
trong môi trường Aquasol với nồng độ $87 \mathrm{mg} / \mathrm{l}$, còn ở công bố của Tatyana (2013) $U$. lactuca được nuôi trong PES. Xiao Jie (2016) đã dùng PES để nuôi $U$. prolifera. Như vậy, có thể thấy PES là môi trường thích hợp cho phát triển $U$. papenfussii.

Ánh sáng thích hợp cho sinh trưởng rong Ulva là mùa xuân và mùa hè (Sousa, 2007). Theo Han (2005), ánh sáng cần thiết cho $U$. pertusa có cường độ $>30 \mu \mathrm{mol}$ photon $/ \mathrm{m}^{2} / \mathrm{s}$, trong đó Tatyana (2013) cho rằng rong $U$. lactuca được nuôi dưới ánh sáng $60 \mu \mathrm{mol}$ photon $/ \mathrm{m}^{2} / \mathrm{s}$ thấp hơn cường độ ánh sáng tự nhiên, trong nghiên cứu của chúng tôi ánh sáng cần thiết $700 \mu \mathrm{mol}$ photon $/ \mathrm{m}^{2} / \mathrm{s}$, còn theo Xiao jie (2016), rong U. prolifera nuôi trực tiếp ngoài trời có ánh sáng là $1.200 \mu \mathrm{mol}$ photon $/ \mathrm{m}^{2} / \mathrm{s}$.

Nhiệt độ thích hợp cho rong sinh trưởng thường là $22-25^{\circ} \mathrm{C}$, trong đó $U$. pertusa ở $25^{\circ} \mathrm{C}$ (Han, 2005), rong $U$. mutabilis ở $22^{\circ} \mathrm{C}$ (Nordby, 1977), và U. lactuca ở $22^{\circ} \mathrm{C}$ (Niesenbaum, 1998). Kết quả nghiên cứu của chúng tôi cho thấy trong khoảng nhiệt độ 22 $25^{\circ} \mathrm{C}$ cũng thích hợp đối với loài $U$. papenfussii.

Độ mặn có ảnh hưởng lớn đến mảnh rong vì chúng tạo nên áp suất thẩm thấu tác động lên đường kính tế bào rong. Theo Han (2005), độ mặn thích hợp cho Ulva sinh trưởng là từ 2,5-3,5\%. Theo Xiao jie (2016), loài $U$. prolifera sinh trưởng tốt ở độ mặn 3,2\%. Kết quả nghiên cứu của chúng tôi cho thấy độ mặn $3 \%$ thích hợp cho $U$. papenfussii.

Tốc độ tăng sinh khối của một số rong Ulva dạng phiến đã được báo cáo trong nhiều công bố. Theo Taylor et al. (2001), tốc độ tăng trưởng của $U$. curvata là $13 \%$ ngày, theo Ale et al., (2011) tốc độ tăng trưởng của $U$. lactuca $16 \%$ ngày, còn $U$. linza là $6,75 \%$ ngày (Kim et al., 2011), U. pertusa là $12 \%$ ngày (Liu, 2010). Tốc độ tăng trưởng của các loài rong này cao từ $6-16 \%$ ngày. Còn kết quả nghiên cứu của chúng tôi cho thấy, tốc độ tăng trưởng của rong $U$. papenfussii là $4,3-$ $6,5 \%$ ngày.

\section{KẾT LUẬN}

Phương pháp phân mảnh trong quá trình sản xuất giông rong $U$. papenfussii bước đầu đã cho được một số kết quả. Rong $U$. papenfussii được phân mảnh thành kích thước $\mathrm{d} 3=1 \times 1$ $\mathrm{cm}$ được giữ ổn định trong chất nền dịch chiết rong Ulva nồng độ $0,1 \mathrm{~g} / 1$ trong thời gian 7 ngày. Sau đó tiếp tục nuôi các mảnh rong trong theo điều kiện: nồng độ mảnh rong $4 \mathrm{~g} / \mathrm{l}$, môi trường PES $20 \mathrm{ml} / \mathrm{l}$, cường độ ánh sáng 700 $\mu \mathrm{mol}$ photon $/ \mathrm{m}^{2} / \mathrm{s}$, nhiệt độ $25^{\circ} \mathrm{C}$, độ mặn $3 \%$, thời gian nuôi 28 ngày. Trong điều kiện nêu trên rong đạt $17,8 \mathrm{~g} / \mathrm{l}$ với tốc độ sinh trưởng cao 4,3-6,5\% ngày.

Lòi cảm ơn: Nhóm tác giả xin chân thành cảm ơn kinh phí hổ trợ của Đề tài Cơ sở 2018VLHCTNB và đề tài hợp tác quốc tế VAST.HTQT.NGA.15-06/16-17 của Viện Nghiên cứu và Úng dụng công nghệ Nha Trang, Viện Hàn lâm Khoa học và Công nghệ Việt Nam.

\section{TÀI LIỆU THAM KHẢO}

Ale M. T., Mikkelsen J. D., Meyer A. S., 2011. Differential growth response of Ulva lactuca to ammonium and nitrate assimilation. J. Appl. Phycol., 23(3): 345-351.

Annette B., Jonas D., Carlos, 2011. Bioenergy potential of Ulva lactuca: Biomass yield, methane productionand combustion. Bioresource Technology,102: 2595-2604.

Brinkhuis B. H., 1985 Handbook of Phycological Methods, Ecological Field Methods: Macroalgae. Cambridge: Cambridge University Press. 461-477.

Dang Diem Hong, Hien H. M. \& Son P. N., 2007. Use of Vietnamese seaweed for functional food, medicine and biofertilizer. J. Applied Phycology, Volume 19, 6: 817-826.

Dawson, 1956. How to know seaweed. Brown company. Iowa., pp. 279.

Han, T. and Choi, G., 2005. Anovel manire algal toxicity bioassay based on sporulation inhibition in the green macroalgae Ulva pertusa(Chlorophyta). Aquat. Toxicol., 75: 202-212. 
Harold C. Bold, Michael J. Wynne, 1978. Introduction to the Algae: Structure and Reproduction. The Quarterly Review of Biology, 53(4): 455-456.

Hiraoka, M. and Entomoto, S., 1998. The induction of reproductive cell formation of Ulva pertusa Kjellman (Ulvales, Ulvophyceae). Phycol. Res., 46: 199-203.

Kim J. H. et al., 2011. Effects of temperature and irradiance on photosynthesis and growth of a green-tide-forming species (Ulva linza) in the Yellow Sea. J Appl Phycol., 23(3): 421-432.

Liu Dongyan, Keesing J. K., Dong Zhijun, et al., 2010. Recurrence of the world's largest green-tide in 2009 in Yellow Sea, China. Mar Pollut Bull., 60(9): 1423-1432.

Niesenbaum, R. A., 1988. The ecology of sporulation by the macroalgae Ulva lactuca L. (Chlorophyceae). Aquat. Bot., 32:155-166.

Nitin T., 2013. Enzymatic hydrolysis and production of bioethanol from common macrophytic green alga Ulva fasciata Delile. Bioresource Technology, 150: 106-112.

Nordby, Q., 1977. Optimal conditions for meiotic spore formation in Ulva mutabilis Foyn. Bot. Mar., 20: 19-28.
Phạm Hoàng Hộ, 1969. Rong biển Việt Nam. Trung tâm Học liệu Sài Gòn, 558 tr.

Sousa, G. M., 1947. On the reproduction of some pacific coast species of Ulva. A. J. Bot., 84: 80-87.

Tatyan Kalita, Eduard A. Titlyanov, 2013. Influence of temperature on the infradian growth rhythm in Ulva lactuca (Chlorophyta). Eur. J. Phycol., 48(2): 210-220.

Taylor R., Fletcher R. L., Raven J. A., 2001. Preliminary studies on the growth of selected 'Green tide' algae in laboratory culture: effects of irradiance, temperature, salinity and nutrients on growth rate. Bot. Mar., 44: 327-336.

Tsutsui Isao, Huỳnh Quang Năng, 2005. The common Marine Plants of Southern Vietnam. Pulished by Japan Seaweed Association, Japan, pp. 250.

Wei N., Quarterman J., Jin Y. S., 2013. Marine macroalgae: an untappedresource for producing fuels and chemicals. Trends in Biotechnology, 31(2): 70-77.

Xiao jie, Zhang Xiaohong, 2016. Effect of temperature, salinity and irradiance on growth and photosynthesis of Ulva prolifera. Acta Oceanol. Sin., 35(10): 114-121. 


\section{PHỤ LỤC HÌNH}

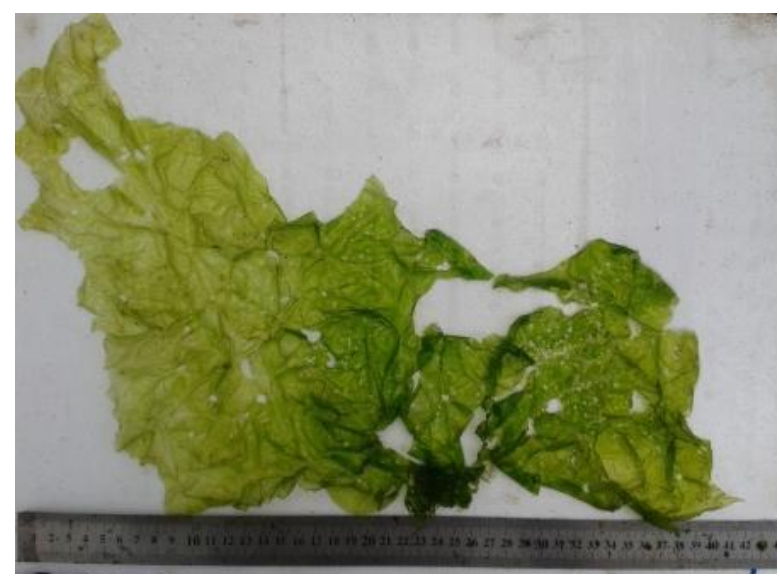

Hình P1. Tản rong Ulva papenfussii

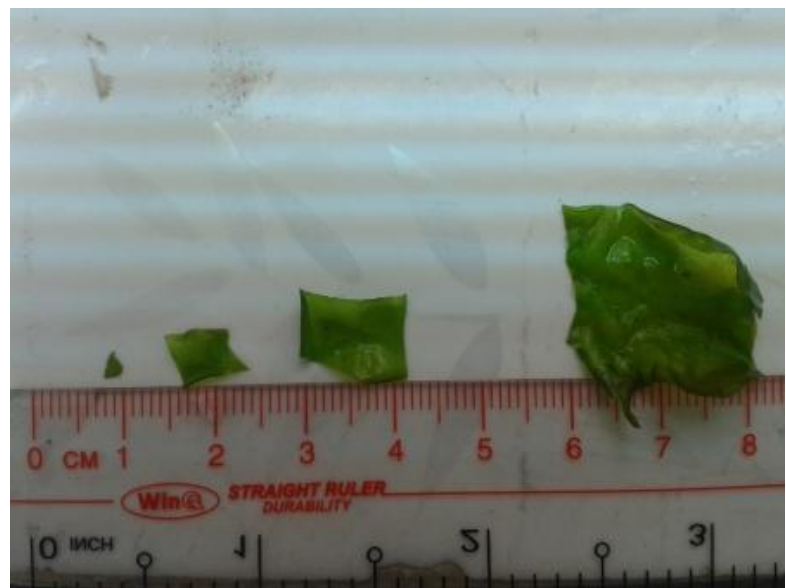

Hình P2. Xử lý mảnh rong (Kích thước $\mathrm{d} 1, \mathrm{~d} 2, \mathrm{~d} 3, \mathrm{~d} 4$ của rong U.papenfussii)



Hình P3. Nuôi dinh dưỡng mảnh rong giống U. papenfussii (Kích thước $\mathrm{d} 1, \mathrm{~d} 2, \mathrm{~d} 3, \mathrm{~d} 4$ của rong U.papenfussii sau khi nuôi được 28 ngày) 